\title{
Pulmonary Vein Occlusion/Stenosis After Pulmonary Vein Ablation for Atrial Fibrillation
}

\author{
HAKAN ORAL, M.D. \\ From the Division of Cardiology, Department of Medicine, University of Michigan, Ann Arbor, Michigan, USA
}

\section{Editorial Comment}

In this issue of the Journal. Ernst et al. ${ }^{1}$ report three cases of total pulmonary vein (PV) occlusion in 239 patients who underwent an ablation procedure for atrial fibrillation (AF). Patients initially were evaluated by internists and pulmonologists and underwent extensive evaluation before the diagnosis was finally made. Despite treatment with thrombolytics, glycoprotein IIb/IIIa inhibitors and anticoagulation, angioplasty, and stenting, restenosis developed. Because imaging studies after a PV ablation procedure were not routinely performed in all patients, the true incidence of PV stenosis and occlusion could not be determined.

PV stenosis may be one of the most serious complications after a PV ablation procedure, as treatment options are limited and restenosis may recur after interventional procedures. Depending on the PV ablation strategy used and whether or not routine imaging studies were performed, the prevalence of PV stenosis has been reported to vary from $0 \%$ to $8 \% .^{2,3}$

\section{Ablation Technique}

In their study, Ernst et al. used a variety of ablation techniques, including substrate modification (right and/or left atrial), focal ablation within a PV, and PV isolation with electroanatomic guidance in different subsets of patients. However, the target temperature and maximum power were set relatively high for radiofrequency energy delivery. Because the risk of PV stenosis is higher when radiofrequency energy is delivered at high temperature and power settings (particularly within a PV), the maximum power and target temperature delivered with a standard, 4-mm-tip radiofrequency ablation catheter have been limited to 30 to $35 \mathrm{~W}$ and $52^{\circ} \mathrm{C}$, respectively, in some centers. . $^{2,4}$

\section{Identification of Target Sites}

In their study, Ernst et al. performed PV angiograms in all left atrial procedures. In addition, with the guidance of an electroanatomic mapping system, virtual tubes were created to represent the PVs. Because the risk of stenosis is higher when radiofrequency energy is delivered within a $\mathrm{PV}^{6}$ and because arrhythmogenic foci within the ostial remnant may cause recurrences of AF, accurate identification of the PV ostia may be the most critical portion of a PV isolation procedure. However, because of the complex three-dimensional relationship of the PVs and the left atrium, identification of

J Cardiovasc Electrophysiol, Vol. 14, pp. 371-372, April 2003.

Address for correspondence: Hakan Oral, M.D., Division of Cardiology, Department of Medicine, University of Michigan, TC B1 140D, 1500 E. Medical Center Drive, Ann Arbor, MI 48109-0311. Fax: 734-936-7026; E-mail: oralh@umich.edu the ostia may be difficult and may require integration of data from a variety of different techniques.

A simple fluoroscopic landmark is the spine, because the PV ostia usually are located on either side of vertebral bodies in the anteroposterior view. Spiral computed tomography or magnetic resonance imaging of the chest with threedimensional reconstruction of the PVs is very helpful in delineating the ostial geometry and identifying anatomic variations such as a common ostium or a separate right middle PV. ${ }^{6}$ Monoplane or biplane venograms can be performed by either selective cannulation of each PV or left atrial injection during adenosine-induced asystole. ${ }^{7}$ However, underfilling or streaming of the contrast agent or selective injection into a branch can be limiting. Another helpful technique is the manual and visual feedback from manipulating a multipolar ring catheter in and out of a vein. When available, real-time impedance measurements usually are higher in the PV than at the ostium or left atrium. Intracardiac echocardiography also has been used to identify the PV ostia. ${ }^{8}$ However, the accuracy of this technique may be suboptimal, given that PV stenosis $>50 \%$ still occurred 4 of 64 patients. ${ }^{8}$

Virtual tubes created with an electroanatomic system do not accurately reflect the caliber or location of the ostia of the PVs. A more accurate method of defining the PV ostia with an electroanatomic mapping system is to create a virtual ring over three points defined at the perimeter of the ostium either with or without the guidance of a circular catheter.

In summary, accurate identification of the PV ostia may be difficult in some patients and may require integration of data from different techniques. Despite rigorous efforts, the ostia may not be precisely identified due to catheter movement distal into the PV or variations in anatomy, in which case PV stenosis may occur.

\section{Clinical Implications}

This report by Ernst et al. has important clinical implications for patients undergoing PV isolation. First, this report underscores the importance of limiting maximum power and target temperature settings. Second, it is important to heighten the awareness of primary care physicians, internists, pulmonologists, and cardiologists to the symptoms and signs of PV stenosis. It also is necessary for electrophysiologists to provide long-term follow-up. Third, the cost efficiency of routine imaging studies after a PV ablation procedure needs to be determined. Perhaps imaging studies should be reserved for patients who develop symptoms or signs suggestive of PV stenosis.

\section{Future Directions}

PV stenoses have been reported after ablation only with radiofrequency energy. Whether alternative sources of energy, 
such as ultrasound, ${ }^{9}$ cryoablation, ${ }^{10}$ or laser energy, carry a similar risk of long-term PV stenosis without a decrease in efficacy remains to be determined. Contact or noncontact three-dimensional mapping systems that can incorporate three-dimensional images obtained from spiral computed tomography or magnetic resonance imaging of the chest may facilitate accurate identification of the PV ostia.

An ablation strategy that creates left atrial ablation lines $>1 \mathrm{~cm}$ from the PV ostia markedly reduces the risk of PV stenosis. ${ }^{11}$ However, the long-term clinical efficacy and safety of this approach in comparison to ostial segmental ablation remain to be determined.

Finally, further studies are necessary to better understand the mechanisms by which PV stenosis and restenosis occur so that effective therapeutic strategies can be developed to treat patients with PV stenosis.

\section{References}

1. Ernst S, Ouyang F, Goya M, Löber F, Schneider C, Hoffmann-Riem M, Schwartz S, Hornig K, Müller K-M, Antz M, Kaukel E, Kugler C, Kuck K-H: Total pulmonary vein occlusion as a consequence of catheter ablation for atrial fibrillation mimicking primary lung disease. J Cardiovasc Electrophysiol 2003;14:366-370.

2. Haissaguerre M, Shah DC, Jais P, Hocini M, Yamane T, Deisenhofer I, Chauvin M, Garrigue S, Clementy J: Electrophysiological breakthroughs from the left atrium to the pulmonary veins. Circulation 2000;102:2463-2465.

3. Gerstenfeld EP, Guerra P, Sparks PB, Hattori K, Lesh MD: Clinical outcome after radiofrequency catheter ablation of focal atrial fibrillation triggers. J Cardiovasc Electrophysiol 2001;12:900-908.
4. Haissaguerre M, Jais P, Shah DC, Garrigue S, Takahashi A, Lavergne T, Hocini M, Peng JT, Roudaut R, Clementy J: Electrophysiological end point for catheter ablation of atrial fibrillation initiated from multiple pulmonary venous foci. Circulation 2000;101:1409-1417.

5. Oral H, Knight BP, Tada H, Ozaydin M, Chugh A, Hassan S, Scharf C, Lai SW, Greenstein R, Pelosi F Jr, Strickberger SA, Morady F: Pulmonary vein isolation for paroxysmal and persistent atrial fibrillation. Circulation 2002;105:1077-1081.

6. Scharf C, Sneider M, Case I, Chugh A, Lai SWK, Pelosi F Jr, Knight BP, Kazerooni E, Morady F, Oral H: Anatomy of the pulmonary veins in patients with atrial fibrillation and effects of segmental ostial ablation analyzed by computed tomography. J Cardiovasc Electrophysiol 2003; $14: 150-155$.

7. Tse HF, Lee KL, Lau CP: Adenosine triphosphate enhanced contrast pulmonary venogram to facilitate pulmonary vein ablation. J Cardiovasc Electrophysiol 2002;13:300.

8. Mangrum JM, Mounsey JP, Kok LC, DiMarco JP, Haines DE: Intracardiac echocardiography-guided, anatomically based radiofrequency ablation of focal atrial fibrillation originating from pulmonary veins. J Am Coll Cardiol 2002;39:1964-1972.

9. Natale A, Pisano E, Shewchik J, Bash D, Fanelli R, Potenza D, Santarelli P, Schweikert R, White R, Saliba W, Kanagaratnam L, Tchou P, Lesh M: First human experience with pulmonary vein isolation using a throughthe-balloon circumferential ultrasound ablation system for recurrent atrial fibrillation. Circulation 2000;102:1879-1882.

10. Rodriguez LM, Geller JC, Tse HF, Timmermans C, Reek S, Lee KL, Ayers GM, Lau CP, Klein HU, Crijns HJ: Acute results of transvenous cryoablation of supraventricular tachycardia (atrial fibrillation, atrial flutter, Wolff-Parkinson-White syndrome, atrioventricular nodal reentry tachycardia). J Cardiovasc Electrophysiol 2002;13:1082-1089.

11. Pappone C, Oreto G, Rosanio S, Vicedomini G, Tocchi M, Gugliotta F, Salvati A, Dicandia C, Calabro MP, Mazzone P, Ficarra E, Di Gioia C, Gulletta S, Nardi S, Santinelli V, Benussi S, Alfieri O: Atrial electroanatomic remodeling after circumferential radiofrequency pulmonary vein ablation: Efficacy of an anatomic approach in a large cohort of patients with atrial fibrillation. Circulation 2001;104:2539-2544. 